\title{
Consistency of long-term elemental carbon trends from thermal and optical measurements in the IMPROVE network
}

\author{
L.-W. A. Chen ${ }^{1,2}$, J. C. Chow $^{1,2}$, J. G. Watson ${ }^{1,2}$, and B. A. Schichtel ${ }^{3}$ \\ ${ }^{1}$ Division of Atmospheric Sciences, Desert Research Institute, 2215 Raggio Parkway, Reno, Nevada 89512, USA \\ ${ }^{2}$ State Key Laboratory of Loess and Quaternary Geology, Institute of Earth Environment, Chinese Academy of Sciences, \\ 10 Fenghui South Road, Xi'an 710075, China \\ ${ }^{3}$ Cooperative Institute for Research in the Atmosphere, Colorado State University, 1375 Campus Delivery, Fort Collins, \\ Colorado 80523, USA
}

Correspondence to: L.-W. A. Chen (antony@dri.edu)

Received: 14 April 2012 - Published in Atmos. Meas. Tech. Discuss.: 31 May 2012

Revised: 27 August 2012 - Accepted: 28 August 2012 - Published: 1 October 2012

\begin{abstract}
Decreasing trends of elemental carbon (EC) have been reported at US Interagency Monitoring of PROtected Visual Environments (IMPROVE) network from 1990 to 2004, consistent with the phase-in of cleaner engines, residential biomass burning technologies, and prescribed burning practices. EC trends for the past decade are examined due to an upgrade of IMPROVE carbon instruments and the thermal/optical analysis protocol since 2005. Filter reflectance $\left(\tau_{R}\right)$ values measured as part of the carbon analysis were retrieved from archived data and compared with EC for 65 sites with more complete records within 2000-2009. EC- $\tau_{R}$ relationships suggest minor changes of EC quantified by the original and upgraded instruments for most IMPROVE samples. EC and $\tau_{R}$ show universal decreasing trends across the US. The EC and $\tau_{R}$ trends are correlated, with national average downward rates (relative to the 2000-2004 baseline medians) of $4.5 \% \mathrm{yr}^{-1}$ for EC and $4.1 \% \mathrm{yr}^{-1}$ for $\tau_{R}$. The consistency between independent $\mathrm{EC}$ and $\tau_{R}$ measurements adds to the weight of evidence that $\mathrm{EC}$ reductions are real rather than an artifact of changes to the measurement process.
\end{abstract}

\section{Introduction}

Elemental carbon (EC), a light-absorbing carbon (LAC) component as determined by thermal/optical methods, is the dominant aerosol fraction that absorbs visible radiation in the troposphere (Andreae and Gelencsér, 2006). This fraction is often termed "black carbon" (BC) if quantified by optical or photoacoustic methods (Moosmüller et al., 2009). EC aerosols from incomplete fuel combustion are non-spherical and internally mixed with organic carbon (OC) (Chakrabarty et al., 2006a, b; Chen et al., 2010). Jacobson (2009) estimates the 100-yr global-warming potential (GWP) of EC+OC from fossil- and bio-fuel combustion to be 800-1300 relative to carbon dioxide $\left(\mathrm{CO}_{2}\right)$. Reducing EC emissions could be a short-term and cost-effective method for slowing global warming (Jacobson, 2002; Bond and Sun, 2005), as well as providing co-benefits for public health, visibility, and material damage (Chow and Watson, 2011).

Long-term monitoring of aerosol chemical composition in the US Interagency Monitoring of PROtected Visual Environments (IMPROVE) network (Watson, 2002) reveals a decreasing trend in average EC concentrations by over $25 \%$ from 1990 to 2004 for the entire country (Murphy et al., 2011) as well as decreases in EC of 40-60\% for urban and non-urban California sites from 1988 to 2007 (Bahadur et al., 2011a, b; Schichtel et al., 2011). These trends are consistent with emission reduction measures implemented to attain $\mathrm{PM}_{2.5}$ and $\mathrm{PM}_{10}$ National Ambient Air Quality Standards for engine exhaust (Lloyd and Cackette, 2001), residential wood combustion (Hough and Kowalczyk, 1983; Butler, 1988; Hough et al., 1988), and prescribed burning (Riebau and Fox, 2001; Tian et al., 2008). Even though IMPROVE data are available through 2009, Murphy et al. (2011) chose to exclude data from 2005 onward owing to potential biases that might have been caused by an upgrade in IMPROVE carbon instruments beginning in 2005. Chow et al. (2007) 


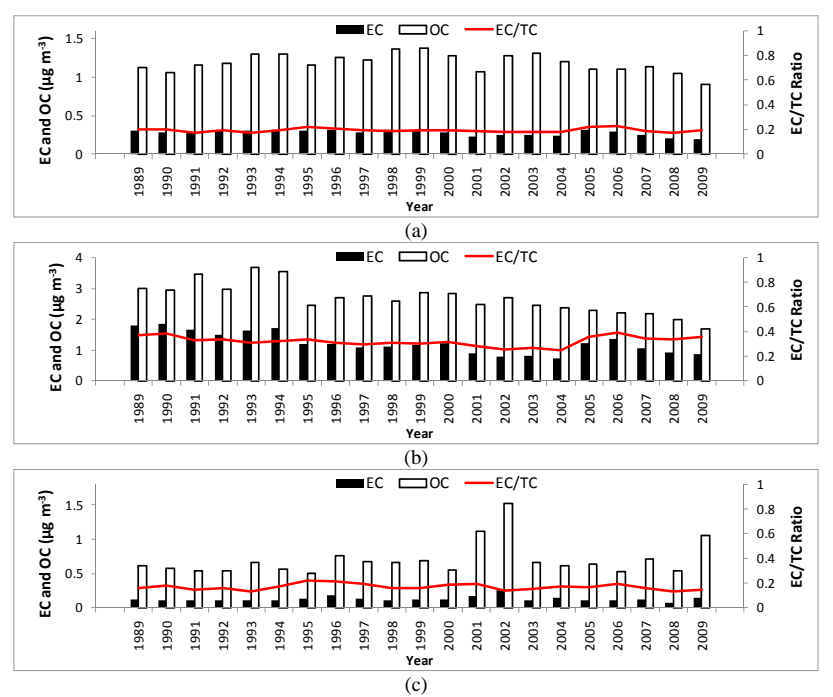

Fig. 1. Annual average elemental carbon (EC), organic carbon (OC), and the ratio of EC to total carbon $(\mathrm{TC}=\mathrm{OC}+\mathrm{EC})$ for: $(\mathbf{a})$ all IMPROVE data, (b) downtown Washington DC (U1), and (c) Bryce Canyon National Park (CP1) between 1989 and 2009. Data were acquired from the Visibility Information Exchange Web System (VIEWS) website (http://views.cira.colostate.edu/). An EC increase from 2004 to 2005 corresponds with the carbon instrument upgrade for (a) and (b), but this is not observed at every site, as shown in (c).

demonstrated equivalence between measurements made with the original (Chow et al., 1993) and upgraded (Chow et al., 2007,2011 ) instruments for hundreds of samples from a variety of environments. However, average EC concentrations and EC/total carbon (TC) ratios increased at some (but not all) IMPROVE sites from 2004 to 2005, as illustrated in Fig. 1. The objective of this study is to investigate the recent (2000-2009) trends in IMPROVE EC along with those of filter reflectance, which serves as an independent surrogate for EC.

The IMPROVE thermal/optical reflectance (TOR) analysis protocol separates EC from OC on filter samples by temperature-dependent volatilization and oxidation. $\mathrm{EC}$ is defined as carbon that does not evolve at $\sim 580{ }^{\circ} \mathrm{C}$ in an inert helium $(\mathrm{He})$ atmosphere and is subsequently oxidized to $\mathrm{CO}_{2}$ with the introduction of oxygen $(2 \%)$ at higher temperatures, up to $840^{\circ} \mathrm{C}$. A fraction of OC chars in the inert atmosphere, as evidenced by decreases in light $(632.8 \mathrm{~nm}$ He-neon $(\mathrm{Ne})$ laser) reflected from the aerosol deposit on the filter surface during the analysis (Fig. 2). Pyrolyzed OC (POC) is defined as the carbon evolved after oxygen is introduced and before the reflected light intensity returns to its original value (i.e., the reflectance crossover). POC is subtracted from apparent EC measurement to yield "native" EC concentration in the sampled air. When all of the carbon has evolved, the remaining filter is usually white, similar to the appearance of a blank

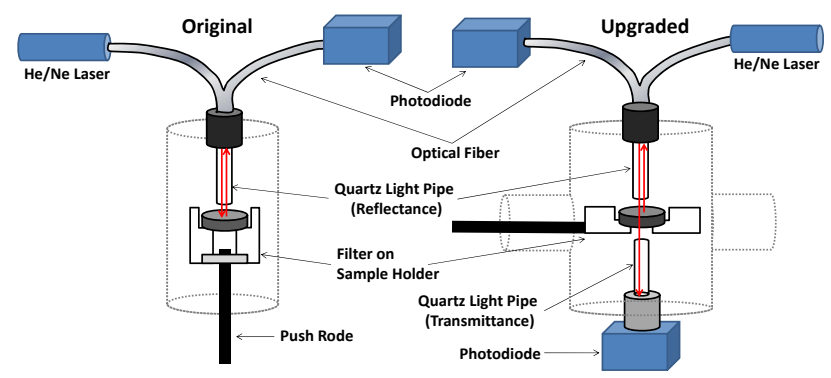

Fig. 2. Schematics of optical monitoring system in the original (left) and upgraded (right) carbon instrument. The laser beam is directed to the sample through a coaxial optical fiber and a quartz light pipe (perpendicular and $\sim 2 \mathrm{~mm}$ to the filter sample) by which the reflected light is acquired. The sample holder is redesigned in the upgraded instrument to allow collection and detection of the transmitted light. The dashed boxes illustrate the heating zone for thermal analysis.

filter. Non-white filters are occasionally found during dust events, and these are flagged as part of the IMPROVE protocol.

The 2005 carbon instrument upgrade led to a transition from the IMPROVE to IMPROVE_A thermal/optical analysis protocol (Chow et al., 1993, 2007). The new protocol did not change the temperatures plateaus but rather reflected "actual" analysis temperatures that had been implemented since the inception of the IMPROVE network (Chow et al., 2005). With improved electronics and sealing, the upgraded instrument allows for more precise temperature control, flexible data acquisition, a higher intensity laser light beam, and lower trace oxygen levels in the inert He atmosphere than did the original instrument (Chow et al., 2011). It also enables simultaneous monitoring of filter reflectance and transmittance without changing the reflectance measurement configuration (Fig. 2). Since 2005, reflectance as well as transmittance crossover has been used for charring correction. Thermal/optical transmittance (TOT) often reports higher POC and lower EC than TOR. Chen et al. (2004) and Chow et al. (2004) attributed this to charring of organic vapors adsorbed within the filter (Watson et al., 2009; Chow et al., 2010) which attenuate transmittance substantially but have a minor effect on reflectance from the surface deposit. EC hereafter refers to TOR EC.

Optical measurements designed for charring correction provide alternatives for quantifying EC or BC abundances on filters. Filter attenuation using reflected light $\left(\tau_{R}\right)$ or transmitted light $\left(\tau_{T}\right)$ is defined as

$\tau_{R}=-\ln \left(R / R_{0}\right)$
$\tau_{T}=-\ln \left(T / T_{0}\right)$,

where $R_{0}$ and $T_{0}$ are reflectance and transmittance, i.e., the reflected and transmitted light intensity, of blank filters, respectively, while $R$ and $T$ are reflected and transmitted light 


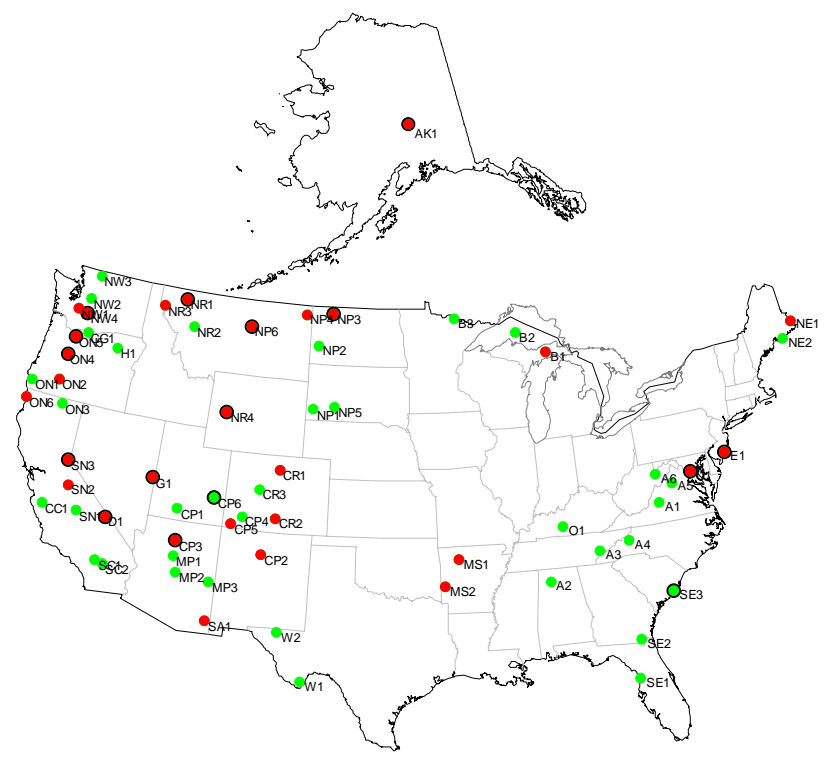

Fig. 3. Sixty-five IMPROVE sites in 25 regions (see Table 1 for definitions). Color codes indicate the changes of EC- $\tau_{R}$ regression coefficients across the instrumental upgrade in 2005. Red: significant change in slope $(p<0.05)$; solid edge: significant change in intercept $(p<0.05)$; green: all other sites without significant changes. See text for details.

intensities of particle-laden filters (prior to carbon analysis), respectively. $\tau_{R}$ or $\tau_{T}$ can be a practically linear function of the light absorption coefficient $\left(b_{\mathrm{abs}}\right)$ for filter samples (Lindberg et al., 1999; Quincey, 2007). The widely deployed aethalometer (Hansen et al., 1984) and particle-soot absorption photometer (PSAP; Bond et al., 1999) estimate $b_{\text {abs }}$ from $\tau_{T}$ that is then converted to $\mathrm{BC}$ loading using assumed mass absorption efficiencies derived from simultaneous EC measurements (Watson et al., 2005 and references therein). $b_{\mathrm{abs}}$ and $\mathrm{BC}$ based on $\tau_{R}$ are also reported (e.g., Edwards et al., 1983; Janssen et al., 2011). $\tau_{R}$ could be more variable in estimating $b_{\mathrm{abs}}$ than $\tau_{T}$ since the angular distribution of reflectance is more sensitive to the chemical composition of particle deposits (Kopp et al., 1999; Petzold and Schönlinner, 2004). Nonlinearity among $b_{\text {abs }}$ (or $\mathrm{BC}$ ), $\tau_{R}$, and $\tau_{T}$ increases with higher sample loading (Arnott et al., 2005) though it was shown in Chen et al. (2004) that the linear relationship between reflectance and transmittance holds up to an EC loading equivalent to $\sim 20 \mu \mathrm{g} \mathrm{cm}^{-2}$ on a filter or $\sim 2 \mu \mathrm{g} \mathrm{m}^{-3}$ in ambient air for IMPROVE network samples $\left(32.7 \mathrm{~m}^{3}\right.$ of air sampled through a $3.53 \mathrm{~cm}^{2}$ filter area).

Since $\tau_{R}$, a measurement of the darkness of the filter deposit, was recorded for every IMPROVE sample before, during, and after the instrument upgrade and is independent of the evolved carbon quantification, it can be used as an independent indicator of EC. Investigating the $\mathrm{EC}$ and $\tau_{R}$ relationship before and after the instrument upgrade is essential. This relationship could be site-, and possibly season-specific,

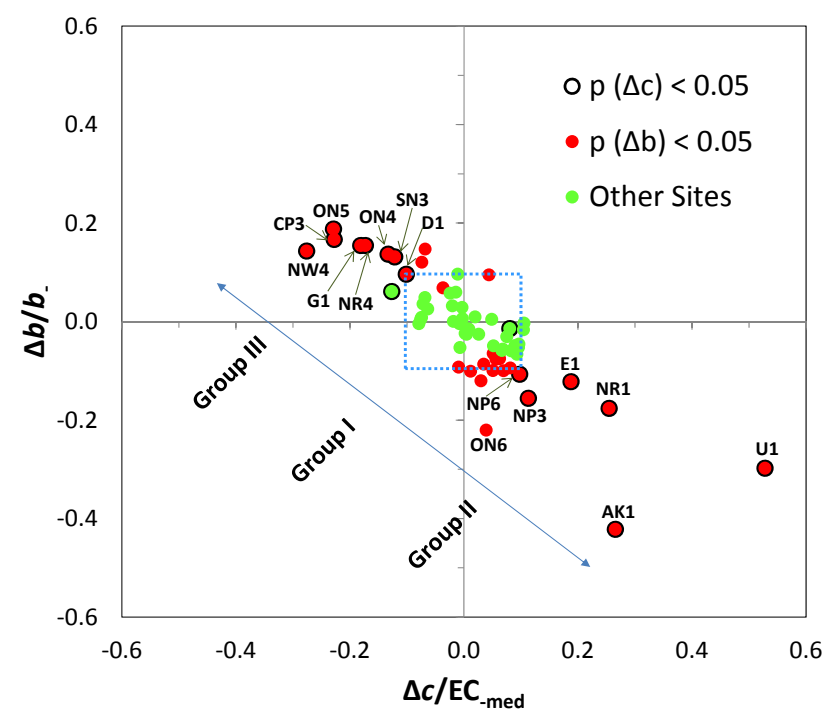

Fig. 4. Changes in EC- $\tau_{R}$ robust regression intercept $(\Delta c)$ /slope $(\Delta b)$ relative to median $\mathrm{EC}\left(\mathrm{EC}_{- \text {med }}\right) /$ regression slope $\left(b_{-}\right)$prior to 2005. Red: significant change in slope $(p<0.05)$; solid edge: significant change in intercept $(p<0.05)$; green: all other sites without significant changes. Group I consists of 36 sites with $\Delta b$ not significantly different from zero. Group II consists of 17 sites with negative $\Delta b$ that are significantly different from zero, and Group III consists of 12 sites with positive $\Delta b$ that are significantly different from zero.

considering the diverse environments represented by IMPROVE samples. Determining $\tau_{R}$ trends provides additional weight of evidence for observed EC trends.

\section{Methodology}

Digital thermograms (which record one second values for temperature, reflectance, and carbon content) for $>83000$ IMPROVE samples acquired by 24 -h sampling on every third day from CY2000 through CY2009 were reprocessed to obtain the initial (dark aerosol deposit) and final (white filter) reflectance values. Data recovery varied by site; typically exceeding $92 \%$ for $2005-2009$, but $\leq 80 \%$ for 2000-2004 due to deteriorating storage media (floppy disks and CD-ROMs; it was not practical to recover data from the paper documentation). The 65 sites with the longest records and highest data recovery rates are listed in Table 1 and used for subsequent analysis. Each of these sites contains 80-120 samples per year (20-30 samples per season). They represent 25 US geographic regions as described in Table 1 (see Fig. 3 for the site locations). $\tau_{R}$ was calculated per Eq. (1) from a ten-second average of the initial and final reflectance for each sample. The final reflectance represents effective $R_{0}$ as all EC has been removed from the filter. 
Table 1. Region, location, and data completeness (2000-2009) of EC and $\tau_{R}$ for 65 IMPROVE sites selected for this study.

\begin{tabular}{|c|c|c|c|c|c|c|c|c|}
\hline \multirow[b]{2}{*}{ Regions } & \multicolumn{6}{|c|}{ Location } & \multicolumn{2}{|c|}{ Data completeness* } \\
\hline & Code & Name & Class I Area & Latitude & Longitude & $\operatorname{MSL}(\mathrm{m})$ & 2000-2004 & $2005-2009$ \\
\hline \multirow[t]{2}{*}{ Northeast } & NE1 & MOOS1 & Moosehorn NWR & 45.1259 & -67.2661 & 77 & $73 \%$ & $97 \%$ \\
\hline & NE2 & ACAD1 & Acadia NP & 44.3771 & -68.261 & 157 & $78 \%$ & $99 \%$ \\
\hline East Coast & E1 & BRIG1 & Brigantine NWR & 39.465 & -74.4492 & 5 & $80 \%$ & $95 \%$ \\
\hline Urban & U1 & WASH1 & Washington D.C. & 38.8762 & -77.0344 & 15 & $71 \%$ & $93 \%$ \\
\hline \multirow[t]{6}{*}{ Appalachia } & $\mathrm{A} 1$ & JARI1 & James River Face Wilderness & 37.6266 & -79.5125 & 289 & $72 \%$ & $99 \%$ \\
\hline & $\mathrm{A} 2$ & SIPS1 & Sipsy Wilderness & 34.3433 & -87.3388 & 286 & $72 \%$ & $92 \%$ \\
\hline & $\mathrm{A} 3$ & GRSM1 & Great Smoky Mountains NP & 35.6334 & -83.9416 & 810 & $73 \%$ & $98 \%$ \\
\hline & A4 & LIGO1 & Linville Gorge & 35.9723 & -81.9331 & 968 & $72 \%$ & $93 \%$ \\
\hline & A5 & SHEN1 & Shenandoah NP & 38.5229 & -78.4348 & 1079 & $73 \%$ & $97 \%$ \\
\hline & A6 & DOSO1 & Dolly Sods Wilderness & 39.1053 & -79.4261 & 1182 & $74 \%$ & $100 \%$ \\
\hline \multirow[t]{3}{*}{ Southeast } & SE1 & CHAS1 & Chassahowitzka NWR & 28.7484 & -82.5549 & 4 & $77 \%$ & $95 \%$ \\
\hline & SE2 & OKEF1 & Okefenokee NWR & 30.7405 & -82.1283 & 48 & $80 \%$ & $98 \%$ \\
\hline & SE3 & ROMA1 & Cape Romain NWR & 32.941 & -79.6572 & 4 & $77 \%$ & $97 \%$ \\
\hline \multirow[t]{3}{*}{ Boundary Waters } & B1 & SENE1 & Seney & 46.2889 & -85.9503 & 214 & $75 \%$ & $97 \%$ \\
\hline & B2 & ISLE1 & Isle Royale NP & 47.4596 & -88.1491 & 182 & $78 \%$ & $96 \%$ \\
\hline & B3 & VOYA1 & Voyageurs NP \#1 & 48.4132 & -92.8303 & 425 & $71 \%$ & $92 \%$ \\
\hline Ohio River Valley & $\mathrm{O} 1$ & MACA1 & Mammoth Cave NP & 37.1318 & -86.1479 & 235 & $75 \%$ & $99 \%$ \\
\hline \multirow{2}{*}{ Mid South } & MS1 & UPBU1 & Upper Buffalo Wilderness & 35.8258 & -93.203 & 722 & $70 \%$ & $95 \%$ \\
\hline & MS2 & CACR1 & Caney Creek & 34.4544 & -94.1429 & 683 & $72 \%$ & $93 \%$ \\
\hline \multirow[t]{6}{*}{ Northern Great Plains } & NP1 & WICA1 & Wind Cave & 43.5576 & -103.484 & 1296 & $71 \%$ & $93 \%$ \\
\hline & NP2 & THRO1 & Theodore Roosevelt & 46.8948 & -103.378 & 852 & $70 \%$ & $97 \%$ \\
\hline & NP3 & LOST1 & Lostwood & 48.6419 & -102.402 & 696 & $76 \%$ & $91 \%$ \\
\hline & NP4 & MELA1 & Medicine Lake & 48.4871 & -104.476 & 606 & $70 \%$ & $96 \%$ \\
\hline & NP5 & BADL1 & Badlands NP & 43.7435 & -101.941 & 736 & $74 \%$ & $99 \%$ \\
\hline & NP6 & ULBE1 & UL Bend & 47.5823 & -108.72 & 891 & $75 \%$ & $95 \%$ \\
\hline \multirow[t]{2}{*}{ West Texas } & W1 & BIBE1 & Big Bend NP & 29.3027 & -103.178 & 1066 & $70 \%$ & $94 \%$ \\
\hline & W2 & GUMO1 & Guadalupe Mountains NP & 31.833 & -104.809 & 1672 & $78 \%$ & $96 \%$ \\
\hline \multirow[t]{3}{*}{ Central Rockies } & CR1 & ROMO2 & Rocky Mountain NP & 40.2783 & -105.546 & 2760 & $74 \%$ & $98 \%$ \\
\hline & CR2 & GRSA1 & Great Sand Dunes NM & 37.7249 & -105.519 & 2498 & $76 \%$ & $93 \%$ \\
\hline & CR3 & WHRI1 & White River NF & 39.1536 & -106.821 & 3413 & $76 \%$ & $96 \%$ \\
\hline Colorado Plateau & $\mathrm{CP} 1$ & BRCA1 & Bryce Canyon NP & 37.6184 & -112.174 & 2481 & $74 \%$ & $95 \%$ \\
\hline & $\mathrm{CP} 2$ & BAND1 & Bandelier NM & 35.7797 & -106.266 & 1988 & $76 \%$ & $94 \%$ \\
\hline & $\mathrm{CP} 3$ & HANC1 & Hance Camp at Grand Canyon NP & 35.9731 & -111.984 & 2267 & $75 \%$ & $96 \%$ \\
\hline & $\mathrm{CP} 4$ & WEMI1 & Weminuche Wilderness & 37.6594 & -107.8 & 2750 & $75 \%$ & $99 \%$ \\
\hline & CP5 & MEVE1 & Mesa Verde NP & 37.1984 & -108.491 & 2172 & $72 \%$ & $96 \%$ \\
\hline & CP6 & CANY1 & Canyonlands NP & 38.4587 & -109.821 & 1798 & $71 \%$ & $93 \%$ \\
\hline Southern Arizona & SAl & CHIR1 & Chiricahua NM & 32.0094 & -109.389 & 1554 & $70 \%$ & $95 \%$ \\
\hline Mogollon Plateau & MP1 & SYCA1 & Sycamore Canyon & 35.1406 & -111.969 & 2046 & $70 \%$ & $94 \%$ \\
\hline & MP2 & IKBA1 & Ike's Backbone & 34.3405 & -111.683 & 1297 & $74 \%$ & $97 \%$ \\
\hline & MP3 & BALD1 & Mount Baldy & 34.0584 & -109.441 & 2508 & $70 \%$ & $96 \%$ \\
\hline Northern Rockies & NR1 & GLAC1 & Glacier NP & 48.5105 & -113.997 & 975 & $74 \%$ & $94 \%$ \\
\hline & NR2 & MONT1 & Monture & 47.1222 & -113.154 & 1282 & $70 \%$ & $96 \%$ \\
\hline & NR3 & CABI1 & Cabinet Mountains & 47.9549 & -115.671 & 1441 & $71 \%$ & $95 \%$ \\
\hline & NR4 & BRID1 & Bridger Wilderness & 42.9749 & -109.758 & 2626 & $78 \%$ & $94 \%$ \\
\hline Great Basin & G1 & GRBA1 & Great Basin NP & 39.0052 & -114.216 & 2065 & $70 \%$ & $96 \%$ \\
\hline Southern California & $\mathrm{SC} 1$ & SAGO1 & San Gorgonio Wilderness & 34.1939 & -116.913 & 1726 & $71 \%$ & $98 \%$ \\
\hline & $\mathrm{SC} 2$ & JOSH1 & Joshua Tree NP & 34.0695 & -116.389 & 1235 & $74 \%$ & $95 \%$ \\
\hline Death Valley & D1 & DEVA1 & Death Valley NP & 36.5089 & -116.848 & 130 & $70 \%$ & $96 \%$ \\
\hline Hell's Canyon & $\mathrm{H} 1$ & STAR1 & Starkey & 45.2249 & -118.513 & 1259 & $74 \%$ & $98 \%$ \\
\hline Sierra Nevada & SN1 & SEQU1 & Sequoia NP & 36.4894 & -118.829 & 519 & $72 \%$ & $96 \%$ \\
\hline & SN2 & YOSE1 & Yosemite NP & 37.7133 & -119.706 & 1603 & $75 \%$ & $94 \%$ \\
\hline & SN3 & BLIS1 & Bliss SP (TRPA) & 38.9761 & -120.103 & 2130 & $71 \%$ & $93 \%$ \\
\hline Columbia River Gorge & CG1 & CORI1 & Columbia River Gorge & 45.6644 & -121.001 & 178 & $76 \%$ & $96 \%$ \\
\hline California Coast & $\mathrm{CC} 1$ & PINN1 & Pinnacles NM & 36.4833 & -121.157 & 302 & $72 \%$ & $97 \%$ \\
\hline Northwest & NW1 & MORA1 & Mount Rainier NP & 46.7583 & -122.124 & 439 & $75 \%$ & $93 \%$ \\
\hline & NW2 & SNPA1 & Snoqualmie Pass & 47.422 & -121.426 & 1049 & $73 \%$ & $97 \%$ \\
\hline & NW3 & NOCA1 & North Cascades & 48.7316 & -121.065 & 568 & $70 \%$ & $94 \%$ \\
\hline & NW4 & WHPA1 & White Pass & 46.6243 & -121.388 & 1827 & $75 \%$ & $95 \%$ \\
\hline Oregon and Northern & ON1 & KALM1 & Kalmiopsis & 42.552 & -124.059 & 80 & $80 \%$ & $98 \%$ \\
\hline California & ON2 & CRLA1 & Crater Lake NP & 42.8958 & -122.136 & 1996 & $70 \%$ & $94 \%$ \\
\hline & ON3 & LABE1 & Lava Beds NM & 41.7117 & -121.507 & 1459 & $70 \%$ & $95 \%$ \\
\hline & ON4 & THSI1 & Three Sisters Wilderness & 44.291 & -122.043 & 885 & $74 \%$ & $98 \%$ \\
\hline & ON5 & MOHO1 & Mount Hood & 45.2888 & -121.784 & 1531 & $78 \%$ & $97 \%$ \\
\hline & ON6 & REDW1 & Redwood NP & 41.5608 & -124.084 & 243 & $70 \%$ & $94 \%$ \\
\hline Alaska & AK1 & DENA1 & Denali NP & 63.7233 & -148.968 & 658 & $75 \%$ & $96 \%$ \\
\hline
\end{tabular}

* Complete $\mathrm{EC}-\tau_{R}$ pairs, where $\mathrm{EC}=$ elemental carbon and $\tau_{R}=-\ln \left(R / R_{0}\right)$ as filter attenuation with respect to reflectance. 
(a)

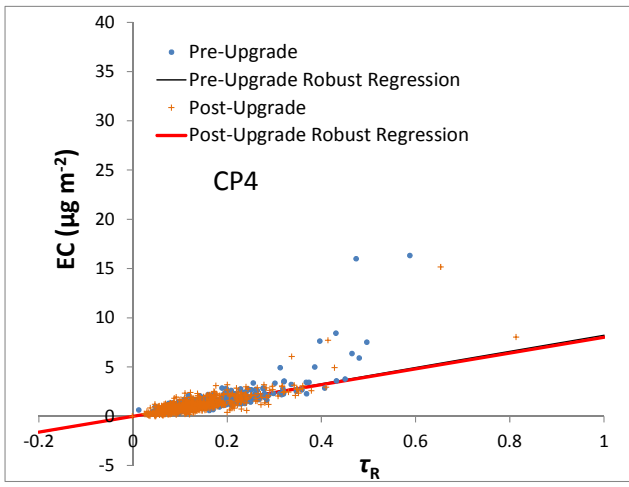

(b)

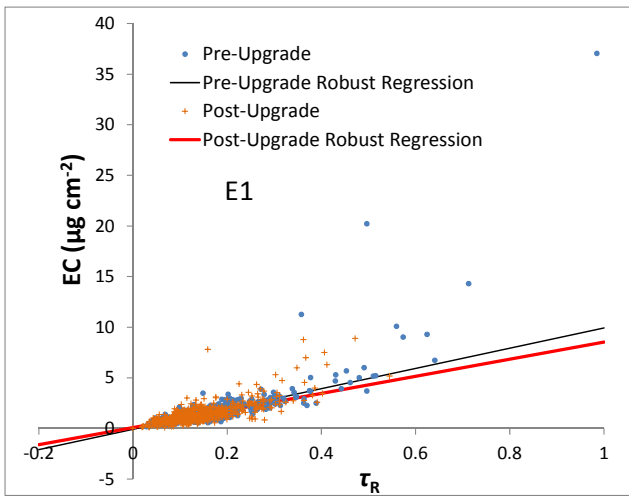

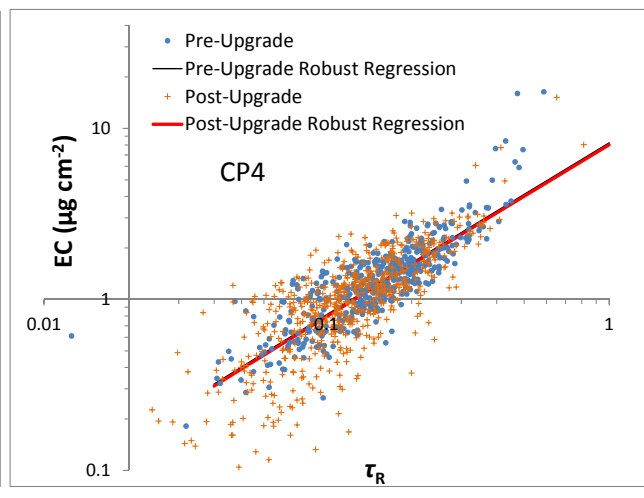

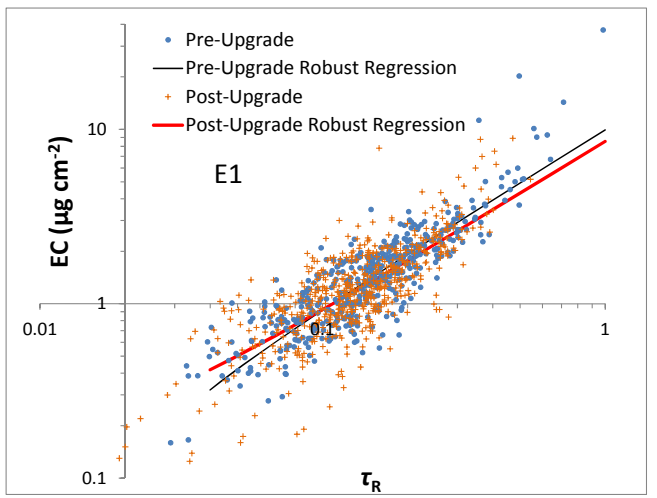

(c)
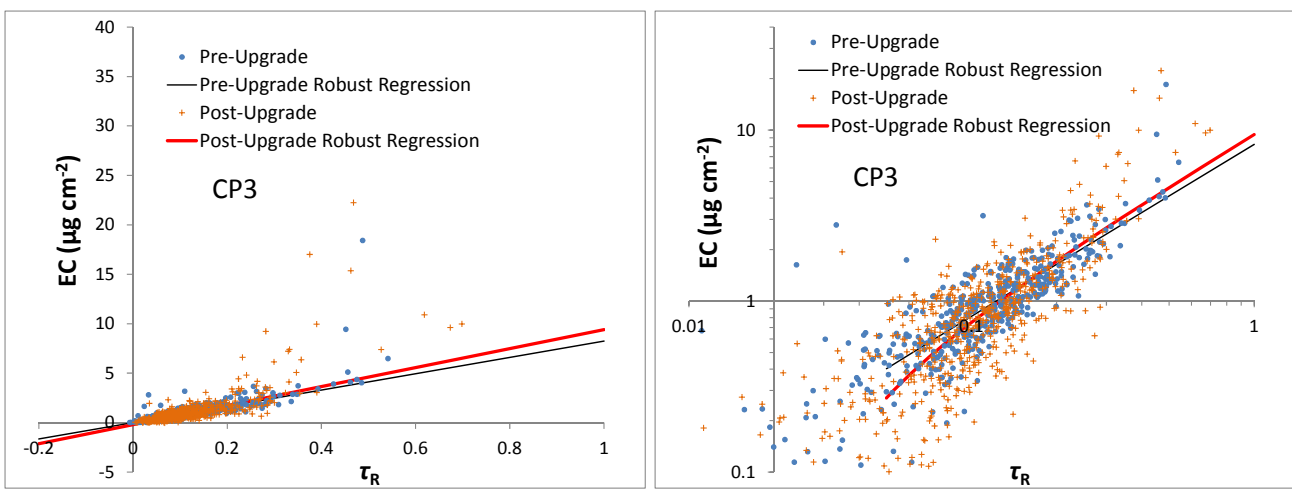

Fig. 5. EC- $\tau_{R}$ scatter for: (a) Wemianche Wilderness (CP4), (b) Brigantine NWR (E1), and (c) Hance Camp at Grand Canyon NP (CP3) as an example of Group I, II, and III sites, respectively. Pre- and post-instrument upgrade periods (i.e., 2000-2004 and 2005-2009, respectively) are separated for robust regression analysis. Left panels: linear scale; right panels: log scale.

Pre- and post-upgrade $\tau_{R}$ at a particular IMPROVE site are related to EC through a linear model:

$$
\begin{aligned}
& \boldsymbol{E} \boldsymbol{C}_{-}=c_{-}+b_{-} \times \boldsymbol{\tau}_{\boldsymbol{R}-} \\
& \boldsymbol{E} \boldsymbol{C}_{+}=c_{+}+b_{+} \times \boldsymbol{\tau}_{\boldsymbol{R}+},
\end{aligned}
$$

where bold italics indicate column vectors of EC or $\tau_{R}$ including all pre (-)/post (+) upgrade (on 1 January 2005) data, and $c$ and $b$ are regression coefficients ( $c$ : intercept; $b$ : slope). $c$ and $b$ are expected to differ (i.e., $c_{+} \neq c_{-}$and/or $b_{+} \neq b_{-}$) only if the instrument upgrade introduced a bias in $\mathrm{EC}$ that is larger than typical measurement uncertainties. To examine the changes in $c$ and $b$, Eqs. (3) and (4) are nested into

$$
\left(\begin{array}{l}
\boldsymbol{E} \boldsymbol{C}_{-} \\
\boldsymbol{E} \boldsymbol{C}_{+}
\end{array}\right)=c_{-}\left(\begin{array}{c}
\boldsymbol{I} \\
\boldsymbol{I}
\end{array}\right)+\Delta c\left(\begin{array}{c}
\boldsymbol{O} \\
\boldsymbol{I}
\end{array}\right)+b_{-}\left(\begin{array}{c}
\boldsymbol{\tau}_{\boldsymbol{R}-} \\
\boldsymbol{\tau}_{\boldsymbol{R}+}
\end{array}\right)+\Delta b\left(\begin{array}{c}
\boldsymbol{O} \\
\boldsymbol{\tau}_{\boldsymbol{R}+}
\end{array}\right)
$$

where $\boldsymbol{I}$ and $\boldsymbol{O}$ are unit and zero column vectors and $\Delta c$ and $\Delta b$ represents $c_{+}-c_{-}$and $b_{+}-b_{-}$, respectively. Meaningful changes in $c$ and $b$ would lead to $\Delta c$ and $\Delta b$ that differ from zero at a statistically significant level (Gujarati, 1970a, b). A robust least-squares regression method that lowers the influence of outliers was applied to determine the coefficients and respective standard errors and p-values in Eq. (5). This 


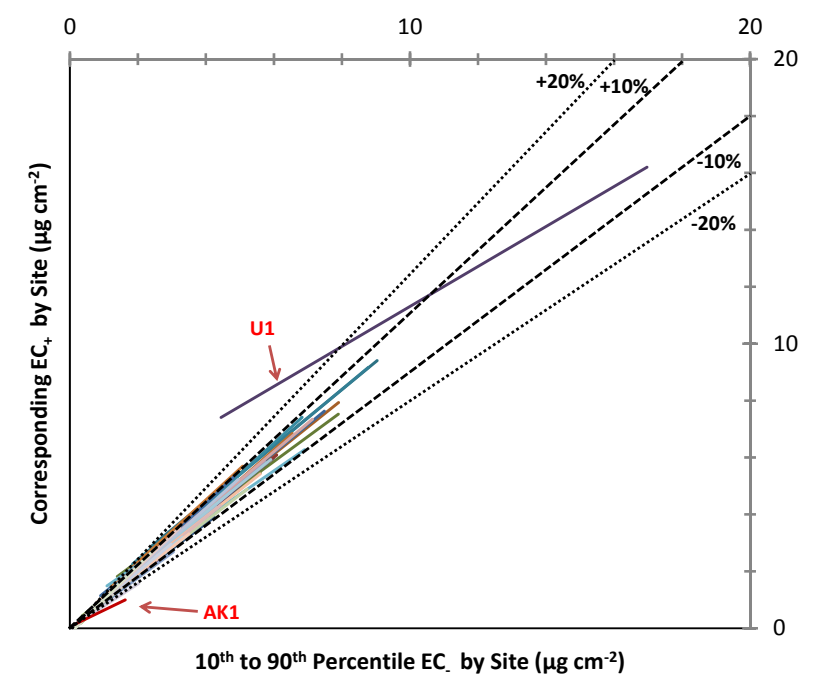

Fig. 6. $\mathrm{EC}_{+}$(after instrument upgrade) vs. EC_ (before upgrade) relationships derived from robust regression analysis. Relationships of $\mathrm{EC}_{+}$and $\mathrm{EC}_{-}$with $\tau_{R}$ are determined separately, and then $\mathrm{EC}_{+}$ is related to $\mathrm{EC}_{-}$by eliminating $\tau_{R}$ in simultaneous equations. Each solid line represents one of the 65 sites stretching from 10th to 90th percentile of EC_. Dashed lines indicate $\pm 10 \%$ or $\pm 20 \%$ deviations.

is achieved by Matlab ${ }^{\circledR}$ robustfit function with the Huber iterative reweighting algorithm (Dutter and Huber, 1981).

Statistical consistency of $c$ and $b$ pre- and post-2005 (i.e., non-significant $\Delta c$ and $\Delta b$ ) result from relatively small $\Delta c$ and $\Delta b$ or large standard errors. The latter suggests an insufficient correlation between EC and $\tau_{R}$ for $\tau_{R}$ to be a good predictor for EC. Therefore, it is important to examine the regression's correlation coefficient as well as the fractional changes in $b$ and $c$, e.g., $\Delta b / b_{-}$and $\Delta c / \mathrm{EC}_{- \text {med }}\left(\mathrm{EC}_{- \text {med }}\right.$ : median $\boldsymbol{E} \boldsymbol{C}_{-}$concentration). $\Delta c / \mathrm{EC}_{- \text {med }}$ is a better evaluation of changes in $\Delta c$ than $\Delta c / c_{-}$since $c_{-}$is usually small to near zero. Lower and Thompson (1988) show that $\boldsymbol{E} \boldsymbol{C}_{+}$can be related to $\boldsymbol{E} \boldsymbol{C}_{-}$by solving Eqs. (3) and (4) after $c$ and $b$ are determined. This relationship would be the best estimate for the relationship between $\boldsymbol{E} \boldsymbol{C}_{+}$and $\boldsymbol{E} \boldsymbol{C}_{-}$, given that a direct regression is not possible.

$\mathrm{EC}$ and $\tau_{R}$ trends were further assessed using a nonparametric Mann-Kendall (M-K) test (Kendall, 1975; Yue et al., 2002), which examines the sign of slopes for all possible data pairs and determines trend significance from the difference in positive and negative signs. All data acquired in the same year are considered as concurrent measurements (ties) in the test to minimize influence of intra-annual trends such as seasonal variations (Salas, 1993). M-K statistics yield Sen's slope (Sen, 1968; Burn and Hag Elnur, 2002), which is the median slope across all possible data pairs, and its p-value and confidence intervals. Sen's slope provides a more quantitative estimate of the trends. M-K statistics were calculated with Matlab ${ }^{\circledR}$ code provided by Burkey (2009).

\section{Results and discussion}

The majority of correlation coefficients $(r)$ of EC versus $\tau_{R}$ from Eq. (5) exceed 0.8 (Table S1 in the Supplement). Lower $r$ is found for Urban, Appalachia, and Ohio River Valley sites with high EC concentrations, especially Washington D.C. (U1 in Fig. 3; $r=0.59$ ) and James River Face Wilderness, Appalachia (A1, $r=0.67$ ). Thirty-six of the 65 sites show no changes in regression slope prior to and after 2005 at the $5 \%$ significance level (i.e., $p(\Delta b)>0.05$ ). Thirty-four of the 36 sites, including all Appalachian sites, show no significant changes in regression intercept prior to and after 2005 (i.e., $p(\Delta c)>0.05) . p(\Delta c)$ are $<0.05$ but $>0.01(1 \%$ significance level) for the remaining two sites (Cape Romain NWR (Southeast, SE3) and Canyonlands NP (Colorado Plateau, CP6), see Table 1 and Fig. 3). The absolute values of $\Delta b$ and $\Delta c$ for these 36 sites are small, generally within $10 \%$ of $b_{-}$and $\mathrm{EC}_{- \text {med }}$, respectively (Group I in Fig. 4). There is no evidence that the instrument upgrade had an effect on EC measurements for samples taken at these sites.

The other 29 sites are separated into two groups according to Fig. 4. Group II (17 sites) exhibits negative $\Delta b$ along with positive $\Delta c$. Six Group II sites have both $\Delta b$ and $\Delta c$ that are significantly different from zero $(p<0.05)$, including Brigantine NWR (E1), Washington DC (U1), Lostwood (NP3), UL Bend (NP6), Glacier NP (NR1), and Denali NP (AK1). These sites are located in eastern (E1, U1), northern, and northwestern states (NP3, NP6, NR1, AK1). Group III (12 sites) exhibits positive $\Delta b$ and mostly negative $\Delta c$. Eight out of 12 Group III sites contain both $\Delta b$ and $\Delta c$ significantly different from zero $(p<0.05)$, including White Pass (NW4), Three Sisters Wilderness (ON4), Mount Hood (ON5), Bliss SP (SN3), Death Valley (D1), Great Basin (G1), Hance Camp at Grand Canyon NP (CP3), and Bridger Wilderness (NR4), all of which are located in the Western Cordillera area of the continental US (Fig. 3). Figure 5 shows examples of EC- $\tau_{R}$ scatter from these three groups.

The POC fraction generally increased for samples analyzed since the beginning of 2005 due to higher purity of the inert $\mathrm{He}$ atmosphere and more rigorous quality control of $\mathrm{He}$ purity (Chow et al., 2007, 2011). Even with the reflectance correction, some POC can be misclassified as EC, thereby increasing the EC fraction. This is more evident when EC/POC ratios are low and would likely move the $\mathrm{EC}-\tau_{R}$ regression towards a higher intercept and lower-to-unchanged slope. Figure 4 is not consistent with this effect being dominant, except possibly at a few Group II sites including the Brigantine NWR site (E1; exemplified in Fig. 5b).

For Group III samples, low EC values tend to be even lower beginning in 2005 for the same $\tau_{R}$ (e.g., Fig. 5c). The reason for this is unclear, though it might be related to different sensitivities of reflectance splits between the original and upgraded instruments for low EC levels. With an improved signal-to-noise ratio of the reflectance measurement, the upgraded instruments possibly trigger the split (crossover) later 

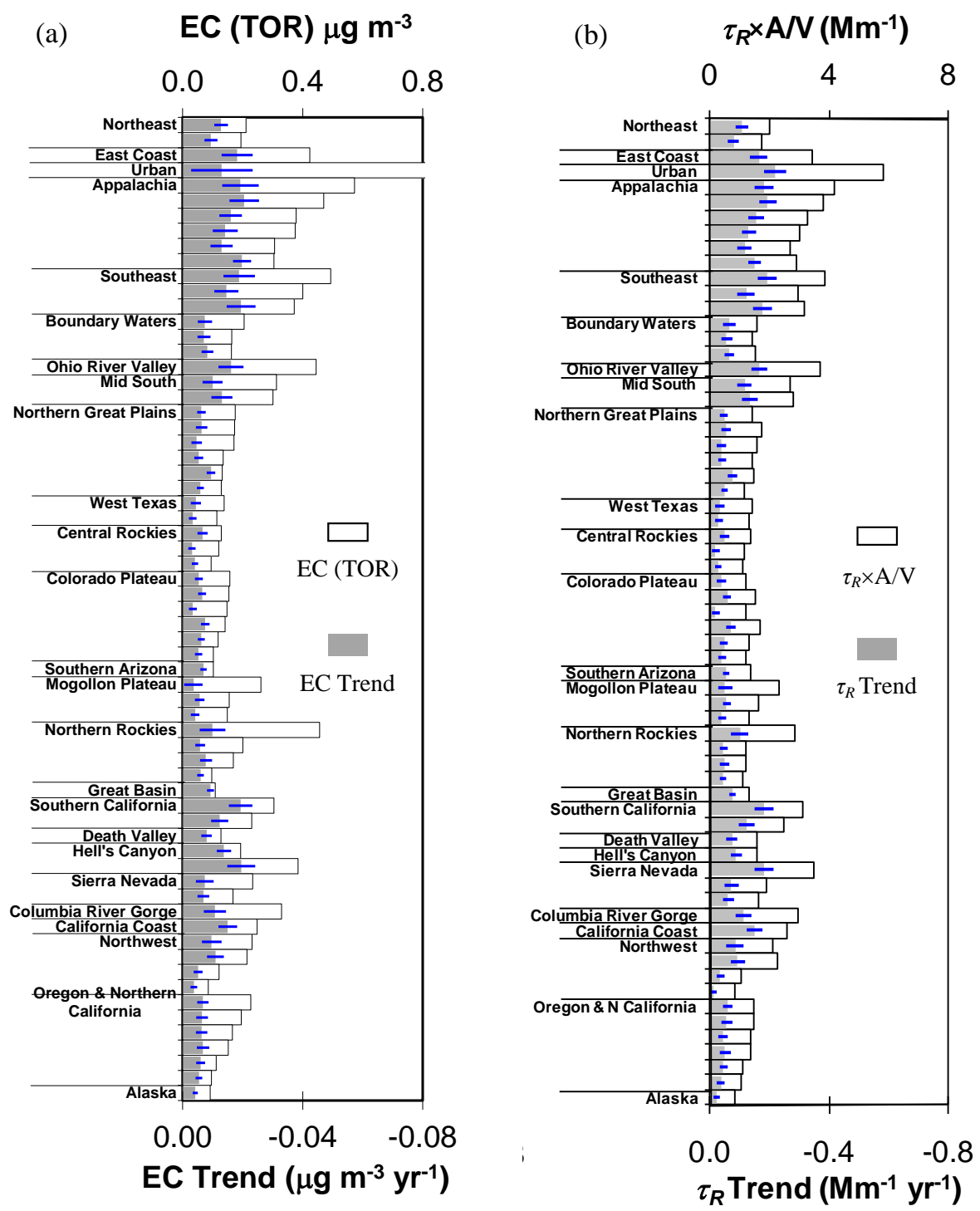

Fig. 7. Median (hollow bar) and trend (solid bar) of: (a) EC by thermal/optical reflectance (TOR) and (b) $\tau_{R}$ at 65 IMPROVE sites. See Table 1 for site details. $A$ and $V$ are nominal filter area $\left(3.53 \mathrm{~cm}^{2}\right)$ and sample volume $\left(32.7 \mathrm{~m}^{3}\right)$, respectively. Medians are those of $2000-$ 2004 baseline period. Trends are based on Sen's slope (2000-2009). The blue bar indicates the $95 \%$ confidence interval of the trend.

than the original instruments, leading to lower EC fractions. $\tau_{R}$ quantification is little influenced by the noise, as both $R$ and $R_{0}$ are averaged over $15 \mathrm{~s}$ before and after the thermal analysis. The opposite effects apparent for Groups II and III could occur simultaneously and offset each other to some extent.

The regression analysis was also carried out by season. However, such seasonal segregation does not reduce scatter around the best-fit lines (Fig. S1 in the Supplement). This suggests daily variability (due to changes in chemical composition and/or measurement uncertainty) comparable to seasonal variability in the EC- $\tau_{R}$ relationship and that yearround regression analyses are reasonably representative of all cases. To test whether extreme EC values due to special events such as wildfires can bias the robust regression, regressions were also calculated excluding EC $>15 \mu \mathrm{g} \mathrm{cm}^{-2}$. This test resulted in only minor changes in regression intercepts and slopes and did not influence the grouping of the 65 sites.

Since the regression slopes increase or decrease while intercepts decrease or increase (i.e., change in opposite direction), $\mathrm{EC}_{+}$may shift higher or lower compared to $\mathrm{EC}_{-}$depending on site and EC loading. Figure 6 shows, by site, the characteristic $\mathrm{EC}_{+}$vs. $\mathrm{EC}_{-}$relationships between the 10th and 90th EC_ concentration percentiles, which contains $80 \%$ of the samples. The linear relationships were derived from Eqs. (3) and (4) by eliminating the common variable $\tau_{R}$, as suggested by Lower and Thompson (1988). $\mathrm{EC}_{+}$is 


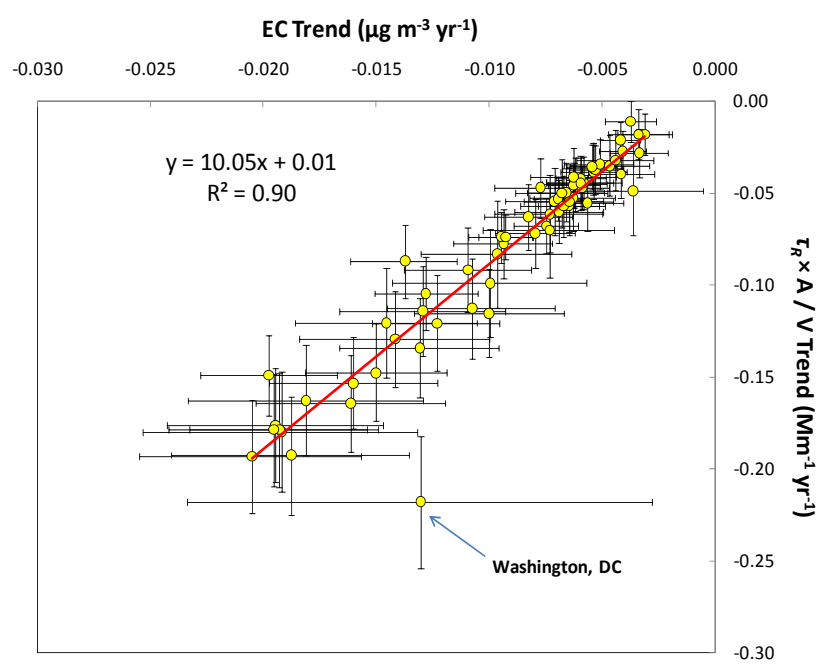

Fig. 8. A comparison of EC and $\tau_{R}$ trends for 65 IMPROVE sites during 2000-2009. $A$ and $V$ are nominal filter area $\left(3.53 \mathrm{~cm}^{2}\right)$ and sample volume $\left(32.7 \mathrm{~m}^{3}\right)$, respectively. Trends are based on Sen's slope and the error bars represent the $95 \%$ confidence intervals.

shown to be within $\pm 10 \%$ of $\mathrm{EC}_{-}$, for the most part. Larger deviations, e.g., $10-20 \%$ or -10 to $-20 \%$, are seen for $\mathrm{EC}_{-} \leq 3 \mu \mathrm{g} \mathrm{cm}^{-2}$. Two extreme outliers are the Washington, DC (U1) and Denali NP (AK1) sites, which experience the highest and lowest EC concentrations, respectively. There seems to be more variability in the EC responses between the original and upgraded instruments for the high and low extremes.

The robust $\mathrm{M}-\mathrm{K}$ test confirms decreasing trends of $\mathrm{EC}$ from 2000 through 2009 (Fig. 7), with the largest and smallest changes observed at one Appalachian (Sipsy Wilderness; A2: $-0.021 \mu \mathrm{g} \mathrm{m}^{-3} \mathrm{yr}^{-1}$ ) and one Central Rockies (Great Sand Dunes, New Mexico; CR2: $-0.003 \mu \mathrm{g} \mathrm{m}^{-3} \mathrm{yr}^{-1}$ ) site, respectively. The trends are statistically significant for all 65 sites at the 5\% significance level. This implies 1.3-8.3\% reduction of ambient EC concentrations each year (scaled to $\mathrm{EC}_{- \text {med }}$ as 2000-2004 represents the IMPROVE network baseline period). The national average trend, calculated from the percentage trends weighted by $\mathrm{EC}_{- \text {med }}$ at each site, would be $-4.5 \%$ per year. With an unweighted ordinary linear regression, Fig. S2 (Supplement) shows median EC decreasing at 3-5\% per year from 2000-2009. Murphy et al. (2011) reported a lower value, $\sim-2.2 \% \mathrm{EC}$ per year, for March 1990-February 2004 for average, rather than median, EC concentrations.

Figure 7 also shows significant decreasing trends $(p<$ $0.05)$ for $\tau_{R}$ at all except one site in the Northwest (White Pass, Washington; NW4) where the p-value is 0.051 for the negative $\tau_{R}$ trend $\left(-0.099 \mathrm{Mm}^{-1} \mathrm{yr}^{-1}\right)$. The EC and $\tau_{R}$ trends are highly correlated, at $r^{2}=0.9$ and slope $=10 \mathrm{~m}^{2} \mathrm{~g}^{-1}$ (Fig. 8). Washington, DC (U1 site), the only urban site in this dataset, is an outlier where $\mathrm{EC}_{+}$seems much higher than $\mathrm{EC}_{-}$based on reflectance (Fig. 6), leading to a smaller EC trend than expected from the $\tau_{R}$ trend. The EC trend at the U1 site contains a large uncertainty, and this may also be the case for other urban sites. The national average $\tau_{R}$ trend, as scaled to $\tau_{R-\text { med }}$ is $-4.1 \%$ each year, also consistent with the national EC trend.

Although subtle changes are found in $\mathrm{EC}-\tau_{R}$ relationships between the pre- and post-2005 periods, the consistency between recent EC and $\tau_{R}$ trends for the majority of IMPROVE sites do not support that such changes have introduced a major or common bias for the EC trends. Environmental changes, probably due to changing EC emissions and year-to-year meteorological variability, are of larger influence than measurement uncertainties. EC concentrations appear to continue decreasing beyond the 1990-2004 period examined by Murphy et al. (2011) at an average rate of 4.1$4.5 \%$ per year. The Regional Haze Rule (US EPA, 1999) has set the goal of returning visibility to natural conditions by 2064. For EC, the natural concentrations are estimated to be $\sim 10 \%$ of the 2000-2004 baseline period. At the current rate of progress, this goal should be met by the 2064 deadline.

\section{Supplementary material related to this article is available online at: http://www.atmos-meas-tech.net/5/ 2329/2012/amt-5-2329-2012-supplement.pdf.}

Acknowledgements. This work was sponsored in part by the National Park Service IMPROVE Carbon Analysis Contract No. C2350000894, and the US EPA task number T2350086187. The conclusions are those of the authors and do not necessarily reflect the views of the sponsoring agencies.

Edited by: W. Maenhaut

\section{References}

Andreae, M. O. and Gelencsér, A.: Black carbon or brown carbon? The nature of light-absorbing carbonaceous aerosols, Atmos. Chem. Phys., 6, 3131-3148, doi:10.5194/acp-6-3131-2006, 2006.

Arnott, W. P., Hamasha, K., Moosmüller, H., Sheridan, P. J., and Ogren, J. A.: Towards aerosol light-absorption measurements with a 7-wavelength Aethalometer: Evaluation with a photoacoustic instrument and 3-wavelength nephelometer, Aerosol Sci. Tech., 39, 17-29, 2005.

Bahadur, R., Feng, Y., Russell, L. M., and Ramanathan, V.: Impact of California's air pollution laws on black carbon and their implications for direct radiative forcing, Atmos. Environ., 45, 11621167, 2011a.

Bahadur, R., Feng, Y., Russell, L. M., and Ramanathan, V.: Response to comments on "Impact of California's air pollution laws on black carbon and their implications for direct radiative forcing" by R. Bahadur et al., Atmos. Environ., 45, 4119-4121, $2011 b$. 
Bond, T. C. and Sun, H. L.: Can reducing black carbon emissions counteract global warming?, Environ. Sci. Technol., 39, 59215926, 2005.

Bond, T. C., Anderson, T. L., and Campbell, D. E.: Calibration and intercomparison of filter-based measurements of visible light absorption by aerosols, Aerosol Sci. Tech., 30, 582-600, 1999.

Burkey, J.: Mann-Kendall Tau-b with Sen's Method (enhanced Matlab code), available at: http:// www.mathworks.com/matlabcentral/fileexchange/

11190-mann-kendall-tau-b-with-sens-method-enhanced (last access: 24 September 2012), 2009.

Burn, D. H. and Hag Elnur, M. A.: Detection of hydrologic trends and variability, J. Hydrol., 255, 107-122, 2002.

Butler, A. T.: Control of woodstoves by state regulation as a fine particulate control strategy, in Transactions, $\mathrm{PM}_{10}$ : Implementation of Standards, edited by: Mathai, C. V. and Stonefield, D. H., Air Pollution Control Association, Pittsburgh, PA, 654-663, 1988.

Chakrabarty, R. K., Moosmüller, H., Arnott, W. P., Garro, M. A., and Walker, J.: Structural and fractal properties of particles emitted from spark ignition engines, Environ. Sci. Technol., 40, 6647-6654, 2006a.

Chakrabarty, R. K., Moosmüller, H., Garro, M. A., Arnott, W. P., Walker, J., Susott, R. A., Babbitt, R. E., Wold, C. E., Lincoln, E. N., and Hao, W. M.: Emissions from the laboratory combustion of wildland fuels: Particle morphology and size, J. Geophys. Res.-Atmos. 111, D07204, doi:10.1029/2005JD006659, $2006 \mathrm{~b}$.

Chen, L.-W. A., Chow, J. C., Watson, J. G., Moosmüller, H., and Arnott, W. P.: Modeling reflectance and transmittance of quartzfiber filter samples containing elemental carbon particles: Implications for thermal/optical analysis, J. Aerosol Sci., 35, 765-780, 2004.

Chen, L.-W. A., Verburg, P., Shackelford, A., Zhu, D., Susfalk, R., Chow, J. C., and Watson, J. G.: Moisture effects on carbon and nitrogen emission from burning of wildland biomass, Atmos. Chem. Phys., 10, 6617-6625, doi:10.5194/acp-10-66172010, 2010.

Chow, J. C. and Watson, J. G.: Air quality management of multiple pollutants and multiple effects, Air Qual. Clim. Change J., 45, 26-32, 2011.

Chow, J. C., Watson, J. G., Pritchett, L. C., Pierson, W. R., Frazier, C. A., and Purcell, R. G.: The DRI Thermal/Optical Reflectance carbon analysis system: Description, evaluation and applications in U.S. air quality studies, Atmos. Environ., 27A, 1185-1201, 1993.

Chow, J. C., Watson, J. G., Chen, L.-W. A., Arnott, W. P., Moosmüller, H., and Fung, K. K.: Equivalence of elemental carbon by Thermal/Optical Reflectance and Transmittance with different temperature protocols, Environ. Sci. Technol., 38, 44144422, 2004.

Chow, J. C., Watson, J. G., Chen, L.-W. A., Paredes-Miranda, G., Chang, M.-C. O., Trimble, D., Fung, K. K., Zhang, H., and Zhen Yu, J.: Refining temperature measures in thermal/optical carbon analysis, Atmos. Chem. Phys., 5, 2961-2972, doi:10.5194/acp5-2961-2005, 2005.

Chow, J. C., Watson, J. G., Chen, L.-W. A., Chang, M. C. O., Robinson, N. F., Trimble, D. L., and Kohl, S. D.: The IMPROVE_A temperature protocol for thermal/optical carbon analysis: Maintaining consistency with a long-term database, J. Air Waste Man- age., 57, 1014-1023, 2007.

Chow, J. C., Watson, J. G., Chen, L.-W. A., Rice, J., and Frank, N. H.: Quantification of $\mathrm{PM}_{2.5}$ organic carbon sampling artifacts in US networks, Atmos. Chem. Phys., 10, 5223-5239, doi:10.5194/acp-10-5223-2010, 2010.

Chow, J. C., Watson, J. G., Robles, J., Wang, X. L., Chen, L.-W. A., Trimble, D. L., Kohl, S. D., Tropp, R. J., and Fung, K. K.: Quality assurance and quality control for thermal/optical analysis of aerosol samples for organic and elemental carbon, Anal. Bioanal. Chem., 401, 3141-3152, 2011.

Dutter, R. and Huber, P. J.: Numerical methods for the non linear robust regression problem, J. Stat. Comput. Sim., 13, 79-113, 1981.

Edwards, J. D., Ogren, J. A., Weiss, R. E., and Charlson, R. J.: Particulate air pollutants: A comparison of British "Smoke" with optical absorption coefficients and elemental carbon concentration, Atmos. Environ., 17, 2337-2341, 1983.

Gujarati, D.: Use of dummy variables in testing for equality between sets of coefficients in two linear regressions: A generalization, Amer. Stat., 24, 18-22, 1970a.

Gujarati, D.: Use of dummy variables in testing for equality between sets of coefficients in two linear regressions: A note, Amer. Stat., 24, 50-52, 1970b.

Hansen, A. D. A., Rosen, H., and Novakov, T.: The aethalometer An instrument for the real-time measurement of optical absorption by aerosol particles, Sci. Total Environ., 36, 191-196, 1984.

Hough, M. L. and Kowalczyk, J. F.: A comprehensive strategy to reduce residential wood burning impacts in small urban communities, JAPCA J. Air Waste Ma., 33, 1121-1125, 1983.

Hough, M. L., Tombleson, B., and Wolgamott, M.: Oregon approach to reducing residential woodsmoke as part of the $\mathrm{PM}_{10}$ strategy, in Transactions, $\mathrm{PM}_{10}$ : Implementation of Standards, edited by: Mathai, C. V. and Stonefield, D. H., Air Pollution Control Association, Pittsburgh, PA, 646-653, 1988.

Jacobson, M. Z.: Control of fossil-fuel particulate black carbon plus organic matter, possibly the most effective method of slowing global warming, J. Geophys. Res., 107, 4410, doi:10.1029/2001JD001376, 2002.

Jacobson, M. Z.: Testimony for U.S. Environmental Protection Agency Public Hearing on the Proposed Endangerment and Cause or Contribute Findings for Greenhouse Gases Under the Clean Air Act, available at: http://www.stanford.edu/group/ efmh/jacobson/PDFfiles/EPAEndang0509.pdf (last access: 24 September 2012), 18 May 2009.

Janssen, N. A. H., Hoek, G., Simic-Lawson, M., Fischer, P., van Bree, L., Ten Brink, H., Keuken, M., Atkinson, R. W., Anderson, H. R., Brunekreef, B., and Cassee, F. R.: Black carbon as an additional indicator of the adverse health effects of airborne particles compared with $\mathrm{PM}_{10}$ and $\mathrm{PM}_{2.5}$, Environ. Health Persp., 119, 1691-1699, 2011.

Kendall, M. G.: Rank Correlation Methods, Griffin, London, UK, 1975.

Kopp, C., Petzold, A., and Niessner, R.: Investigation of the specific attenuation cross-section of aerosols deposited on fiber filters with a polar photometer to determine black carbon, J. Aerosol Sci., 30, 1153-1163, 1999.

Lindberg, J. D., Douglass, R. E., and Garvey, D. M.: Atmospheric particulate absorption and black carbon measurement, Appl. Optics, 38, 2369-2376, 1999. 
Lloyd, A. C. and Cackette, T. A.: Critical review - Diesel engines: Environmental impact and control, J. Air Waste Manage., 51, 809-847, 2001.

Lower, W. R. and Thompson, W. A.: An indirect test of correlation, Environ. Toxicol. Chem., 7, 77-80, 1988.

Moosmüller, H., Chakrabarty, R. K., and Arnott, W. P.: Aerosol light absorption and its measurement: A review, J. Quant. Spectrosc. Ra., 110, 844-878, 2009.

Murphy, D. M., Chow, J. C., Leibensperger, E. M., Malm, W. C., Pitchford, M., Schichtel, B. A., Watson, J. G., and White, W. H.: Decreases in elemental carbon and fine particle mass in the United States, Atmos. Chem. Phys., 11, 4679-4686, doi:10.5194/acp-11-4679-2011, 2011.

Petzold, A. and Schönlinner, M.: Multi-angle absorption photometry - A new method for the measurement of aerosol light absorption and atmospheric black carbon, J. Aerosol Sci., 35, 421-441, 2004.

Quincey, P. G.: A relationship between Black Smoke Index and Black Carbon concentration, Atmos. Environ., 41, 7964-7968, 2007.

Riebau, A. R. and Fox, D.: The new smoke management, Int. J. Wildland Fire, 10, 415-427, 2001.

Salas, J. D.: Analysis and modeling of hydrologic time series, in: Handbook of Hydrology, edited by: Maidment, D. R., McGrawHill, Columbus, OH, 19.1-19.63, 1993.
Schichtel, B. A., Pitchford, M. L., and White, W. H.: Comments on "Impact of California's Air Pollution Laws on Black Carbon and their Implications for Direct Radiative Forcing” by R. Bahadur et al., Atmos. Environ., 45, 4116-4118, 2011.

Sen, P. K.: Estimates of the regression coefficient based on Kendall's tau, J. Am. Stat. Assoc., 63, 1379-1389, 1968.

Tian, D., Wang, Y. H., Bergin, M., Hu, Y. T., Liu, Y. Q., and Russell, A. G.: Air quality impacts from prescribed forest fires under different management practices, Environ. Sci. Technol., 42, 2767-2772, 2008.

US EPA: 40 CFR Part 51 - Regional haze regulations: Final rule, Federal Register, Environmental Protection Agency, Washington, DC, 64, 35714-35774, 1999.

Watson, J. G.: Visibility: Science and regulation - 2002 Critical Review, J. Air Waste Manage., 52, 628-713, 2002.

Watson, J. G., Chow, J. C., and Chen, L.-W. A.: Summary of organic and elemental carbon/black carbon analysis methods and intercomparisons, Aerosol Air Qual. Res., 5, 65-102, 2005.

Watson, J. G., Chow, J. C., Chen, L.-W. A., and Frank, N. H.: Methods to assess carbonaceous aerosol sampling artifacts for IMPROVE and other long-term networks, J. Air Waste Manage., 59, 898-911, 2009.

Yue, S., Pilon, P., and Cavadias, G.: Power of the Mann-Kendall and Spearman's rho tests for detecting monotonic trends in hydrological series, J. Hydrol., 259, 254-271, 2002. 